\title{
A CONSTITUTIVE MODEL FOR NATURAL SOFT CLAY WITH STRAIN SOFTENING
}

\author{
Fusao OKa ${ }^{i)}$, S. LeroueiL ${ }^{i 1}$ and F. Tavenas ${ }^{(1)}$
}

\begin{abstract}
A constitutive model of natural soft clay with strain softening, which is an important feature of overconsolidated clay, has been developed based on the concept of elasto-plasticity with memory. A new stress history tensor, which denotes a memory of stress with respect to strain, has been introduced by use of a strain measure. The stress history tensor is effective for discribing the deformation feature of frictional materials with strain softening. By using this stress history tensor, we extend the elasto-plasticity theory of overconsolidated clays previously proposed by Oka et al. The proposed model is capable of describing the strain-hardening and strain-softening behavior of natural soft clays in the overconsolidated region, and was applied to the triaxial drained and undrained behavior of a Champlain sea clay from eastern Canada. The comparison between volumetric and axial strain responses of experiment and simulation shows good agreement.
\end{abstract}

Key words : clay, constitutive equation of soil, over nsolidation, plasticity, strain softening, stress-strain curve, triaxial compression (IGC : D 6/D 5)

\section{INTRODUCTION}

Although many constitutive relations of clays have been proposed in recent years (ISSMFE Subcommittee, 1985), there are still several problems to be solved. One of them relates to the strain-softening behavior during the deformation process of overconsolidated clay and soft rocks. In general, natural overconsolidated clays and rock-like materials show strain-hardening and strainsoftening behavior during the plastic deformation process. The stress-strain curves obtained on natural soft clay after consolida- tion at small stresses exhibit strain-softening after peak strength is reached while CID tests carried out after consolidation at higher stresses show strain hardening behavior (e. g. Tavenas and Leroueil, 1977). Softening behavior is an important phenomenon for the design problem in relation to the estimation of bearing capacity, stability problems and the capability of deformation.

In the framework of continuum mechanics, there are several approaches to describe the strain-hardening and strain-softening behavior. Many researchers have explained the strain-softening behavior by using the theory

1) Professor, Department of Civil Engineering, Gifu University, Yanagido 1-1, Gifu 501-11.

i) Professor, Department of Civil Engineering, Laval University, Québec G1K 7 P 4, Canada. Manuscript was received for review on July 9, 1988.

Written discussions on this paper should be submitted before April 1, 1990, to the Japanese Society of Soil Mechanics and Foundation Engineering, Sugayama Bldg. 4F, Kanda Awaji-cho 2-23, Chiyoda-ku, Tokyo 101, Japan. Upon request the closing date may be extended one month. 
of plasticity (Nayak and Zienkiewicz, 1972 ; Prévost and Höeg, 1977; Bannerjee and Stipho, 1979 ; Dragon and Mróz, 1979 ; Kawahara et al., 1981 ; Matsumoto and Ko, 1982). Pietruszczak and Mróz (1981) dealed with the softening problem by introducing the smear element in finite element method to avoid the mesh size dependency of the analysis. Valanis (1982) showed that endochronic theory also can predict the strainsoftening behavior of soil. Valanis (1985) presented the uniqueness of solution of initial value problem in softening materials, and Willam et al. (1987) addressed the uniqueness and stability of strain-softening computations. For the mesh size dependency problem, Bažant et al. (1988) developed a partially nonlocal continuum formulation to overcome

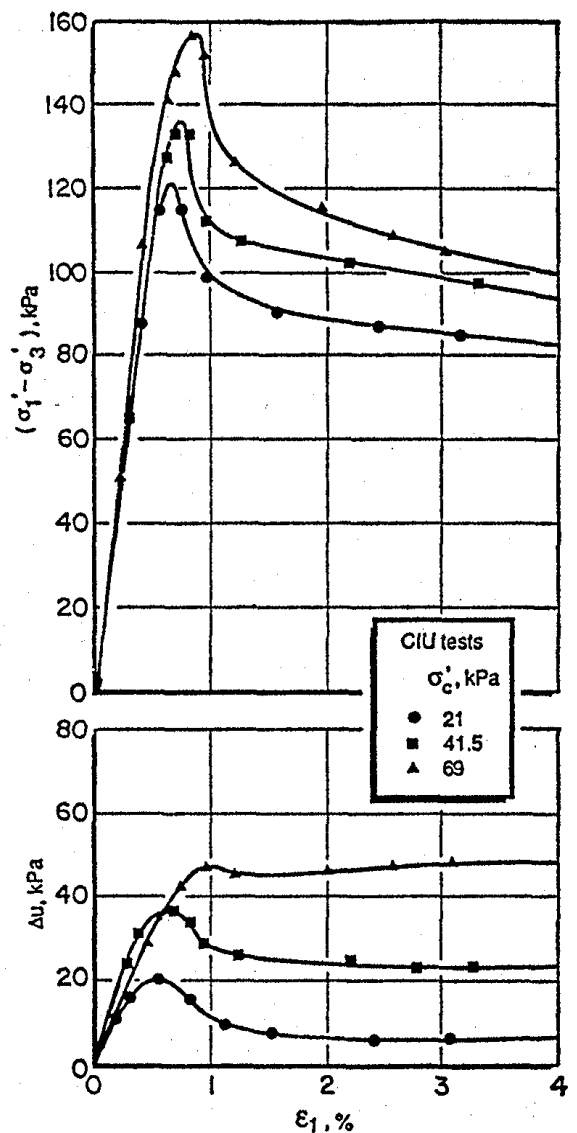

(a)

$\sigma_{c}$ confining pressure
$\Delta u$ excess pore water
pressure
$\Delta v / v_{0}$ volumetric strain

Fig. 1. Triaxial test results obtained on the Saint-Vallier clay, a-CIU tests; b-CID tests (After Lefebvre, 1970) this difficulty.

Oka (1985) developed an elasto-viscoplasticity theory with internal variables and memory based on the generalized simple body (Wang, 1969) to take into account the acceleration creep behavior of materials. Thereafter, Oka and Adachi (1985) proposed a rate-independent elasto-plastic constitutive equation of soft rocks with memory in order to explain the strain-hardening and strainsoftennig behavior based on the concepts of generalized simple body and the intrinsic time measure used in the endochronic theory (Valanis, 1971).

The aim of the present paper is to construct a constitutive model of natural overconsolidated clay with strain-softening extending Oka and Adachi's approach (1985 b).

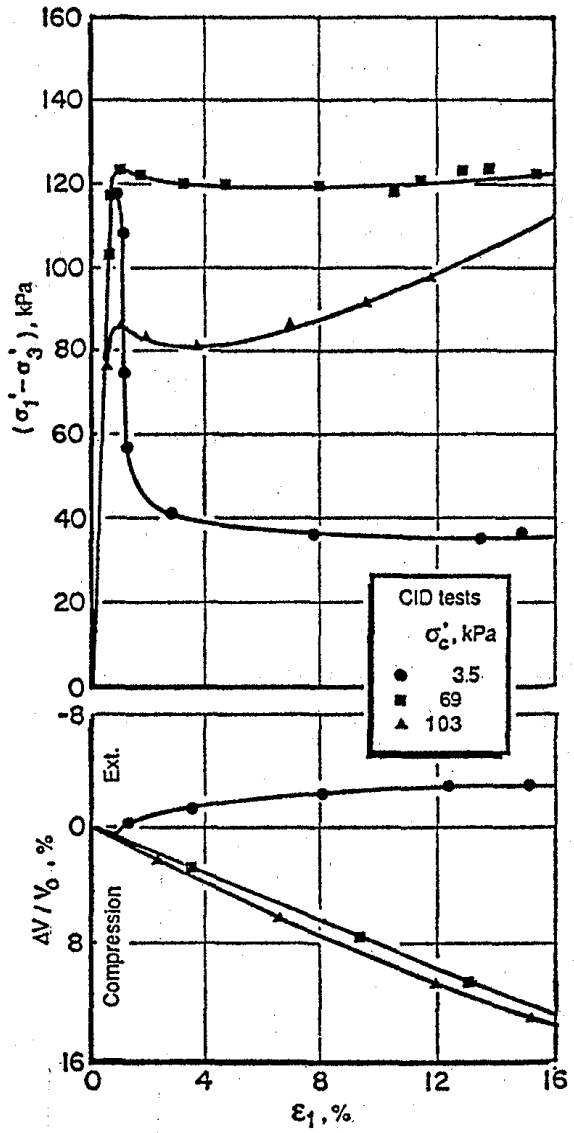

(b) 
The proposed model has been applied to simulate the drained and undrained triaxial compression test results obtained on a natural soft overconsolidated clay from Louiseville (Québec). Comparison of experimental and calculated results shows that the proposed model effectively simulates the deformation behavior of natural soft clay.

\section{BEHAVIOR OF NATURAL SOFT CLAYS}

Many studies on the stress-strain behavior of natural soft clays have been performed in the last two decades. They generally confirm the validity of the basic concepts of limit and critical states first suggested by Roscoe et al. (1958), but they also show that, for natural clays, it is necessary to extend these basic concepts to incorporate anisotropy, structure and time or strain rate effects (Tavenas and Leroueil, 1977 ; Leroueil et al., 1979 ; Larsson, 1981 ; Magnan et al., 1982 ; Graham et al., 1983 ; Tavenas and Leroueil, 1987).

When testing natural clays in their overconsolidated state, the behavior obviously reflects all these phenomena. The results obtained by Lefebvre (1970), Lefebvre and La Rochelle (1974), on the Saint-Vallier clay from the Province of Québec will be used to illustrate the observed behavior. More detailed analysis of this behavior is given by El Moustassim (1986).

Fig. 1(a) shows CIU(consolidated isotropically undrained triaxial test) test results. All the stress-strain curves present well defined

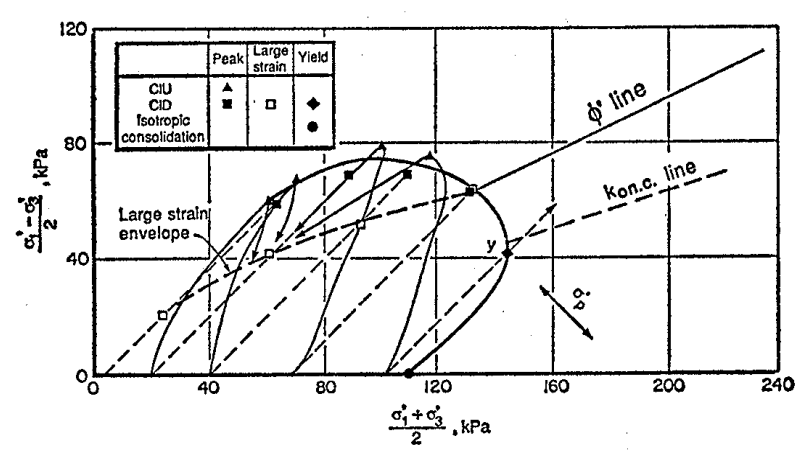

Fig. 2. Stress paths and limit state curve-Saint Vallier clay (After Lefebvre, 1970)

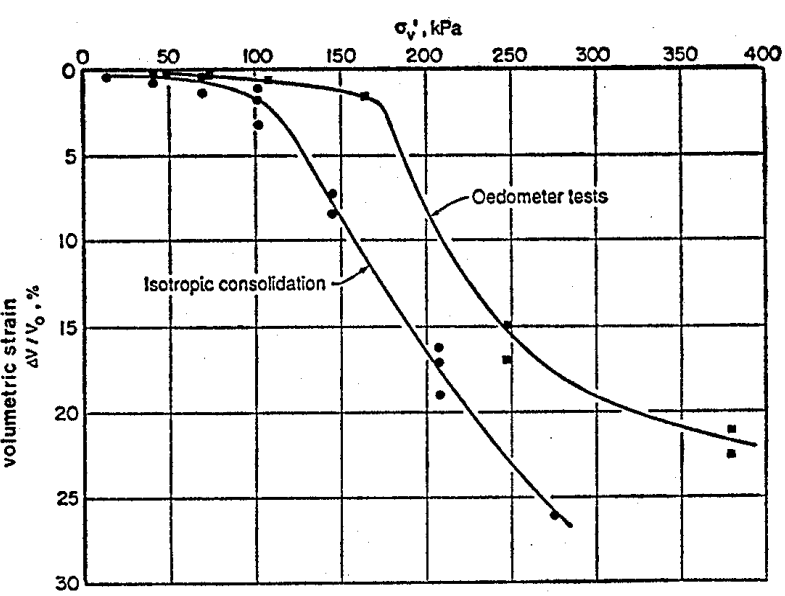

Fig. 3. Consolidation tests on the SaintVallier clay (After Lefebvre, 1970)

peaks at small strain, followed by strain softening. The pore water pressure generated increases with the consolidation stress. As shown on Fig. 2, on which the stress path are plotted, the peak strength define a curved peak-strength envelope. At large strains, all the stress paths converge towards the same stress area well below the peak strength envelope.

Fig. 3 shows the results of two oedometer tests and of triaxial isotropic consolidation tests; both curves have well defined yielding stresses at a vertical stress respectively of 183 and $112 \mathrm{kPa}$ for the oedometric and isotropic consolidation tests. The ratio of these two yield stresses, equal to 1.63 is typical of natural soft clays (Leroueil and Tavenas, 1977 ; Leroueil et al., 1983). These yielding stresses together with the peak strengths obtained in CIU tests and experience with similar clays allow the drawing of the entire yield curve which is more or less centered on the $K_{0, n . c}$. line (Fig. 2).

Fig. 1(b) shows CID (consolidated isotropically drained triaxial test) test results. The specimen consolidated under $3.5 \mathrm{kPa}$ shows a well defined peak with an important strain-softening; the peak and large strain strength are indicated on Fig. 2. The specimen consolidated under $103 \mathrm{kPa}$ presents first a quasi-elastic behavior until the stress path reaches the yield curve (point $y$ on Fig. 2), then it develops a strain hardening behavior, 


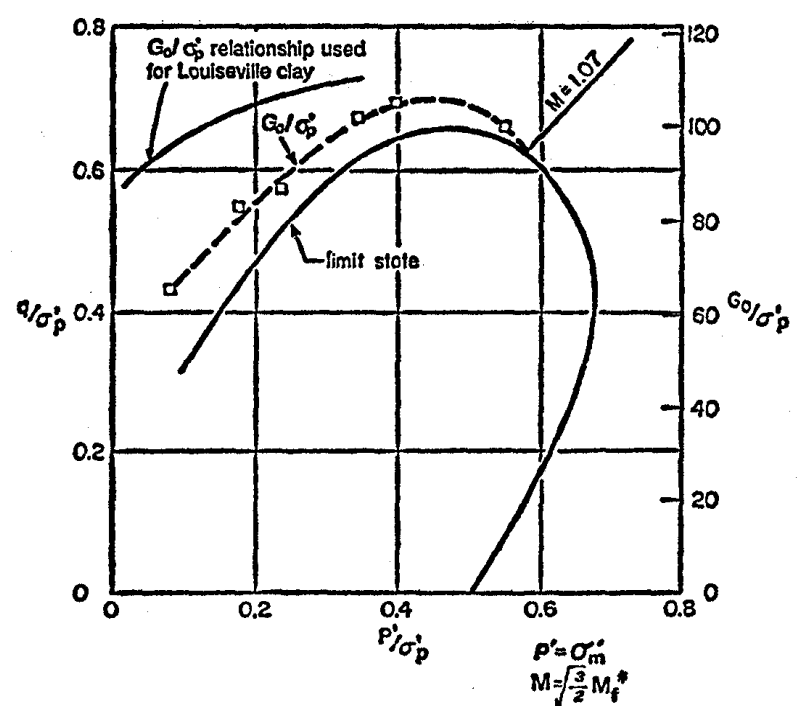

Fig. 4. Interrelation between normalized limit state and shear moduli in the Saint-Alban clay (from Tavenas and Leroueil, 1979)

going towards the $\phi^{\prime}$ line of the normally consolidated clay. The specimen consolidated under $69 \mathrm{kPa}$ (Fig. 2) reaches the yield curve and the $\phi^{\prime}$ line at the same time and consequently presents an elastic perfectly plastic behavior (Fig.1(b)). The peaks obtained in these CID tests are slightly lower than the peaks obtained in CIU tests, which is due to strain rate effects, the rate used in these CID tests being five times slower than in CIU tests (Lo and Morin, 1972 ; Tavenas and Leroueil, 1977). As indicated by Lefebvre and La Rochelle (1974) and by Tremblay (1983) the strength envelope obtained in CID tests at large strain is curved (Fig. 2).

It is finally interesting to mention that the stress-strain relations before yielding are not linear and that the initial shear modulus $G_{0}$ is not a constant in the overconsolidated range. As indicated by Tavenas and Leroueil (1979), $G_{0}$ is strongly influenced by the shape of peak strength envelope (Fig. 4).

\section{GENERAL DESCRIPTION OF THE CONSTITUTIVE MODEL}

Rate-independent deformation process of natural soft clay is assumed to be described by the stress, stress-history tensor and internal variables. Total strain increment tensor $d \varepsilon_{i j}$ is assumed to be composed of three components, the external elastic strain increment tensor $d \varepsilon_{i j} j^{e x}$, plastic strain increment tensor $d \varepsilon_{i j} j^{p}$ and the internal elastic strain increment tensor $d \varepsilon_{i j}{ }^{i e}$. The concept of internal elastic strain is introduced since the failure of microstructure generally relates to the elastic properties of the material. On the other hand, the microstructural change related to plastic deformation is not influenced by external elastic strain.

$$
\begin{aligned}
& d \varepsilon_{i j}=d \varepsilon_{i j}{ }^{e x}+d \varepsilon_{i j}{ }^{i n} \\
& d \varepsilon_{i j}{ }^{i n}=d \varepsilon_{i j} j^{i e}+d \varepsilon_{i j} j^{p}
\end{aligned}
$$

in which $d \varepsilon_{i j}{ }^{i n}$ is the internal strain increment tensor that affects the plastic deformation or microstructural change.

In order to define the stress history tensor, the strain measure which is similar to the intrinsic time measure advocated by Valanis (1971, 1982), is used instead of real time. Herein, the strain measure $z$ is defined by

$$
d z=P_{i j k_{l}} d \varepsilon_{i j}{ }^{i n} d \varepsilon_{k_{l}}{ }^{i n}
$$

in which $P_{i j k l}$ is a fourth order positive definite tensor.

We introduce a stress history tensor, $S^{*}$, which is a functional of stress history. If the stress history tensor $S^{*}$ is a continuous functional of the stress history $S^{z}$, the following form can be taken.

$$
\begin{gathered}
S^{*}=\int_{-\infty}^{z} K\left(z-z^{\prime},[W]\right) S^{z}\left(z^{\prime}\right) d z^{\prime} \\
S^{z}=\left(S\left(z-z^{\prime}\right) ; 0 \leqq z^{\prime}<\infty\right)
\end{gathered}
$$

in which $S$ is the stress tensor and $[W]$ denotes other state variables. In Eq. (4), the scaler kernel function $K($.$) can be$ generally expressed by a distribution function $D(z)$ as

$$
K(z)=\int_{0}^{\infty} \frac{D\left(\tau^{\prime}\right)}{\tau^{\prime}} \exp \left(-z / \tau^{\prime}\right) d \tau
$$

All constitutive functionals are assumed to be functional of the present stress, the stress history tensor and the internal state variables. The plastic strain tensor is introduced as a second order internal variable tensor. The evolutional equation is introduced for 
the plastic deformation on the basis of the non-associated flow rule. Indeed experimental data on natural clays are indicating the deviations from the normality (Wong and Mitchell, 1975 ; Fauveau-Brucy, 1977 ; Graham et al., 1983 ; Felix et al., 1985). For overconsolidated clay, Pender (1977) showed the effectiveness of non-associated flow rule, and thereafter, Stipho (1980), Ohmaki (1980) and Akai, Adachi and Oka (1981) constructed constitutive models based on the nonassociated fiow rule. It must be recognized that the non-associated flow rule demands the increase in number of material parameters, however, it gives a great advantage to explain the stress-strain behavior of soil (see Lade, 1987). The non-associated flow rule is given by

$$
d \varepsilon_{i j}^{p}=h \frac{\partial f_{p}}{\partial S_{i j}} d f_{y}
$$

in which $f_{v}$ is the yield function, $f_{p}$ the plastic potential function, $h$ the strainhardening and strain-softening function, $S_{i j}$ the stress tensor and $d \varepsilon_{i j}{ }^{p}$ the plastic strain increment tensor.

The subsequent yield function $f_{y}$ is in general an intricate function of the state variables. In this paper, the subsequent yield function is a function of the stress history tensor, stress tensor and the strainhardening and strain-softening parameters.

$$
f_{y}\left(S_{i j} * S_{i j}, \kappa_{s}\right)=0
$$

In Eq. (8), strain-hardening and strainsoftening scalar parameter $\kappa_{s}$ is related to the plastic strain through the following equation.

$$
\kappa_{s}=\kappa_{s}\left(\varepsilon_{i j}^{p}\right)
$$

Taking into account the external and internal elastic components of strain increment tensor, we get an elasto-plastic constitutive model with stress-memory with respect to strain measure.

\section{CONSTITUTIVE MODEL FOR NATU- RAL OVERCONSOLIDATED CLAY}

Although many constitutive models have been proposed for normally consolidated clay,

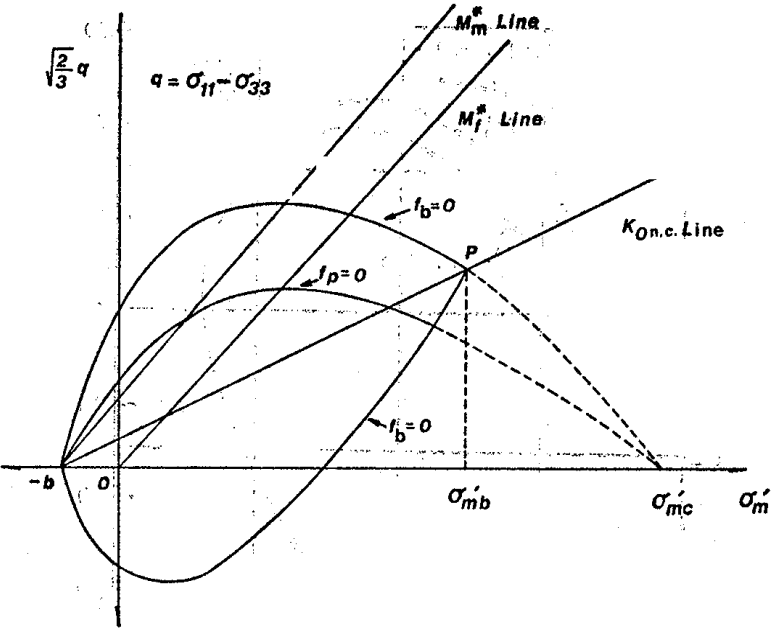

Fig. 5. Overconsolidated boundary surface and plastic potential

theoretical studies on constitutive model for overconsolidated clay are relatively limited. Natural clays have been overconsolidated to some degree due to many reasons, such as stress release, cementation, thixotropic hardening, variation in water level or drying. The strain-hardening and strainsoftening behavior of soft natural clay is essentially associated with overconsolidation. To describe the strain-softening behavior of clay, some models have been developed in the framework of continuum mechanics. However, these models have to be validated. with comparison with experimental data and improved to couple shearing and dilatancy, and incorporate three-dimensional behavior. Adachi and Oka (1984) proposed a constitutive equation for sand and overconsolidated clay without strain-softening based on the elasto-plastic theory.

In this section, this model will be combined with the constitutive model proposed in the previous section to construct a constitutive model for the behavior of soft natural clay that exhibits strain-hardening and strainsoftening behavior.

An overconsolidated boundary surface that defines the boundary between overconsolidated $\left(f_{b}<0\right)$ and the normally consolidated $\left(f_{b} \geqq 0\right)$ regions as shown in Fig. 5 has been introduced. This boundary surface is similar to what has been called limit state surface in the first part of the paper. In this paper, 
we have assumed that the limit state surface is equal to the boundary surface.

The boundary surface is written by

$$
f_{b}=\bar{\eta}_{(0)}+M_{m} * \ln \left[\left(\sigma_{m}{ }^{\prime}+b\right) /\left(\sigma_{m b}{ }^{\prime}+b\right)\right]=0 \text {, }
$$

in which $b$ is the material parameter corresponding to the intersection of the upper part of the boundary surface with the $\sigma_{m}$ ' axis (Fig. 5) and $\bar{\eta}_{(0)}$ is the relative stress ratio parameter, which is a variant of stress ratio parameter $\eta$ first introduced by Sekiguchi and Ohta (1977), expressed by

$$
\begin{gathered}
\bar{\eta}_{(0)}=\left[\left(\eta_{i j}-\eta_{i j(0)}\right)\left(\eta_{i j}-\eta_{i j(0)}\right)\right]^{1 / 2} \\
\eta_{i j}=s_{i j} / \sigma_{m}{ }^{\prime} \\
\eta=\left(\eta_{i j} \eta_{i j}\right)^{1 / 2}
\end{gathered}
$$

In the above relations, $\eta_{i j}$ is the stress ratio tensor, $s_{i j}$ is the deviatoric stress tensor and $\sigma_{m}{ }^{\prime}$ is the mean effective stress, and $\eta_{i j(0)}$ is the value of $\eta_{i j}$ at the end of $K_{0}$ consolidation in the normally consolidated range.

In Eq. (10), $\sigma_{m b^{\prime}}$ can be determined by the vertical preconsolidation stress $\sigma_{p}{ }^{\prime}$ and $K_{0, n . c}$. value, and is also related to $\sigma_{m c} c^{\prime}$ in Fig. 5 through the following relation:

$$
\sigma_{m b}{ }^{\prime}=\sigma_{m c}{ }^{\prime} \exp \left(-\eta_{(0)} / M_{m}{ }^{*}\right)
$$

where $\eta_{(0)}$ is a value of $\eta$ at point $P$ in Fig. 5.

According to Eq. (4), the stress history tensor $\sigma_{i j}{ }^{*}$ is expressed by use of an exponential type kernel function as follows:

$$
\sigma_{i j}{ }^{*}=\frac{1}{\tau} \int_{0}^{z} \exp \left(\frac{-\left(z-z^{\prime}\right)}{\tau}\right) \sigma_{i j}\left(z^{\prime}\right) d z^{\prime}
$$

in which $z$ is a strain measure defined by

$$
d z=\left(d e_{i j} d e_{i j}\right)^{1 / 2}
$$

where $d e_{i j}$ is a deviatoric internal strain increment tensor.

In Eq. (15), $\tau$ is a material parameter, which expresses the retardation of transformed stress $\sigma_{i j} *$ to real stress $\sigma_{i j}$ with respect to strain measure $z$ and controls the degree of strain-softening. The difference between $\sigma_{i j}{ }^{*}$ and $\sigma_{i j}$ depends on the value of $\tau$. This type of stress history tensor satisfies the principle of fading memory (Christensen, 1982). This stress history tensor controls the frictional component of strength. In general, in the stiff geological materials, the degree of damaging is small in the early part of the straining and the frictional resistance is also small. On the other hand, the degree of damaging becomes large and the frictional resistance develops with the increase of strain. Correspondingly, the value of $\sigma_{i j}{ }^{*}$ is small in the early part of deformation and becomes large in the large strain state. Now, we are considering the shear deformation. Therefore, we used the strain measure by deviatoric strain. However, the definition of the strain measure can be generalized or specified taking account of the physical process of deformation. In this paper, the external elastic strain rate is neglected for simplicity, because we do not deal with behavior under the cyclic loadings.

Referring to previous works on overconsolidated clay for constitutive relations (Pender, 1977 ; Ohmaki, 1980 ; Oka and Washizu, 1981 ; Adachi and Oka, 1984), it is assumed that the material behaves elastically in the overconsolidated region only when the stress ratio is kept constant. Considering these previous works, the plastic yield function can be written as:

$$
f_{y}=\hat{\eta}^{*}-\kappa_{s}=0 .
$$

where $\hat{\eta}^{*}$ is a stress ratio history invariant given by

$$
\begin{aligned}
& \hat{\eta}^{*}=\left(\hat{\eta}_{i \jmath} * \hat{\eta}_{i \jmath}\right)^{1 / 2} \\
& \hat{\eta}_{i j}{ }^{*}=s_{i \jmath}{ }^{*} / \sigma_{m}{ }^{*}
\end{aligned}
$$

in which $s_{i j}{ }^{*}$ is a deviatoric component of $\sigma_{i j}{ }^{*}$ and $\sigma_{\mathrm{m}}{ }^{* *}$ is spherical component of $\sigma_{i j}{ }^{*}$. For loading condition, it is implicitly assumed that the plastic deformation occurs only when $d f_{y}>0$. In this case, $d z$ is always positive. From a physical point of view, this assumption corresponds to the fact that the straining is a cause of the micro-structural change or plastic deformation of the materials. Strain-hardening and -softening parameter $\kappa_{s}$ is assumed to increase with the increase of the plastic deviatoric strain invariant as

$$
\kappa_{s}=\frac{M_{f}^{*} G^{\prime} \gamma^{p *}}{M_{f}^{*}+G^{\prime} \gamma^{p *}}
$$

The hyperbolic type of stress-strain relation has been widely accepted for explaining the 
deformation behavior of soils by many researchers (Kondner, 1963 ; Nishi, 1978 ; Adachi and Oka, 1984 etc.). In Eq. (20), $M_{f}^{*}$ is a value of stress ratio parameter at the large strain strength state and $\gamma^{p *}$ is the plastic strain invariant;

$$
\gamma^{p *}=\left(e_{i j}^{p} e_{i j}^{p}\right)^{1 / 2}
$$

where $e_{i j} j^{p}$ is a plastic deviatoric strain tensor.

Based on the previous study on overconsolidated clays, the following plastic potential function is used.

$$
f_{p}=\eta+\tilde{M}^{*} \ln \left[\left(\sigma_{m}{ }^{\prime}+b\right) /\left(\sigma_{m c}{ }^{\prime}+b\right)\right]=0
$$

where $\tilde{M}^{*}$ can be obtained by

$$
\widetilde{M}^{*}=-\frac{\eta}{\ln \left[\left(\sigma_{m}{ }^{\prime}+b\right) /\left(\sigma_{m c}{ }^{\prime}+b\right)\right]}
$$

In the above relations, $\sigma_{m c}{ }^{\prime}$ is obtained from the preconsolidation pressure through Eqs. (10) and (14). We add to Eq. (23) the assumption that $\tilde{M}^{*}=M_{m} *$ is always valid after the stress state has reached the normally consolidated region $f_{b} \geqq 0$.

Taking into account the elastic component of strain rate, we get the total strain rate. The elastic strain increment is given by

$$
d \varepsilon_{i j}{ }^{i e}=\frac{1}{2 G} d s_{i j}+\frac{\kappa}{3(1+e) \sigma_{m}^{\prime}} d \sigma_{m}^{\prime} \delta_{i j}
$$

where $G$ is an elastic shear modulus, $e$ is a void ratio and $\kappa$ is a swelling index.

It is worth noting that the stress history tensor $\sigma_{i j}{ }^{*}$ becomes the stress tensor $\sigma_{i j}$ when $\tau \rightarrow 0$. In this case, the proposed theory automatically becomes the usual elasticplastic constitutive model by Adachi and Oka (1984) with no strain softening. As for the method of the determination of the value of $\tau$, we have taken a curve-fitting method. However, it is possible to use a suitable optimization technique to determine the value of $\tau$.

\section{SIMULATION OF CHAMPLAIN CLAY BEHAVIOR}

In this section, the proposed theory is applied to the triaxial tests carried out on the Louiseville clay. Louiseville is located on the North shore of the Saint-Laurent river, about $170 \mathrm{~km}$ from Quebec city and $88 \mathrm{~km}$ from Montreal. The clay deposit has been formed 12000-8500 years before present and is rather massive and homogeneous (Tavenas et al., 1983).

\section{SOIL PROPERTIES}

The main properties of the clay studied, taken at a depth of $10 \mathrm{~m}$, are given in Table 1 ; it is a highly plastic clay with a water content of $69 \%$ and a liquidity index of 1.07 . The preconsolidation pressure $\sigma p^{\prime}$ is equal to $180 \mathrm{kPa}$ and the sensitivity is equal to 22 . Fig. 6 shows the limit state curve of the clay as defined from three CIDC, two CIUC and one anisotropic consolidation $\left(\sigma_{3}{ }^{\prime} / \sigma_{1}{ }^{\prime}=\right.$ 0.5) triaxial tests. The swelling index $\kappa$ was determined from this last test; the volumetric plastic strain parameter could also be defined from this test in the normally consolidated region, this aspect has not been considered. Because the present study is dealing only with the overconsolidated range.

As indicated previously, six triaxial tests have been performed on the Louiseville clay and they will be numerically simulated by use of the model proposed in the previous section. The material parameters used in the calculation are listed in Table 2 ; they can be described as follows : $-\sigma_{m(0)}{ }^{\prime}$ is the consolidation mean effective stress; except for the CAUC test, the consolidation was isotropic ; $-G$, the elastic shear modulus varies with the applied stress (Tavenas and Leroueil, 1979) ; it has been chosen as shown in Fig. 4 ;

Table 1. Properties for Louiseville clay

\begin{tabular}{lc} 
Water content $w_{0}(\%)$ & 69 \\
Void ratio $e_{0}$ & 1.90 \\
Liquid limit $w_{L}(\%)$ & 66 \\
Plastic limit $w_{p}(\%)$ & 26 \\
Plastic index $I_{p}(\%)$ & 40 \\
Specific density $G_{s}$ & 2.77 \\
Clay fraction $(\%)$ & $73 \sim 85$ \\
Silt fraction $(\%)$ & $15 \sim 27$ \\
Sensitivity $S_{t}$ & 22 \\
Preconsolidation pressure $\sigma_{p}^{\prime}(\mathrm{kPa})$ & 180 \\
Friction angle (degree) in the normally & \\
$\quad$ consolidated range & 30 \\
Permeability $k(\mathrm{~m} / \mathrm{s})$ & $9 \times 10^{-10}$ \\
\hline
\end{tabular}




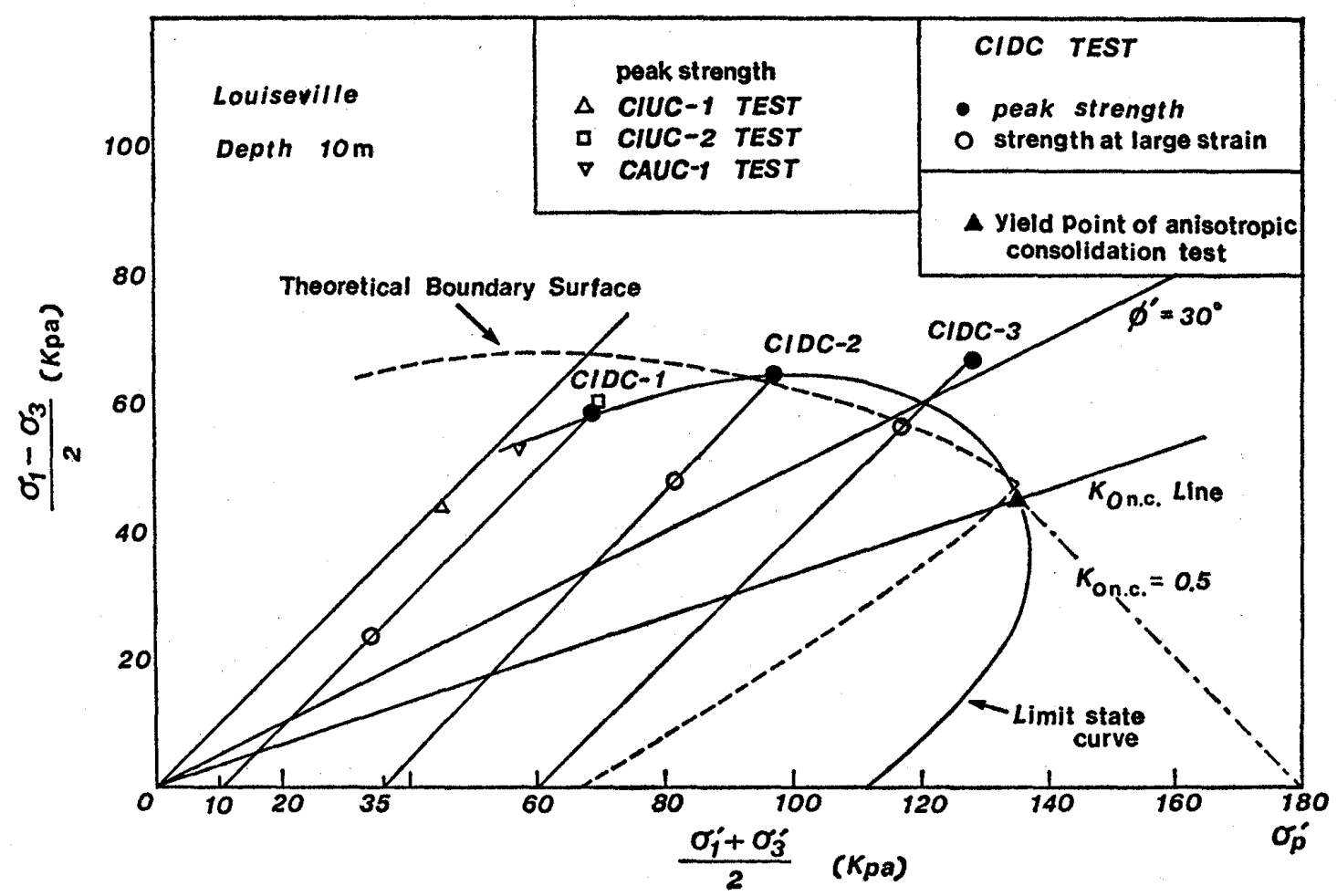

Fig. 6. Limit state surface and stress paths for CIDC tests-Louisevill clay

Table 2. Material parameters used in the calculation

\begin{tabular}{lccccccc}
\hline Test No. & $\begin{array}{c}\sigma_{m(0)}^{\prime} \\
\mathrm{kPa}\end{array}$ & $\begin{array}{c}G_{0} \\
\mathrm{kPa}\end{array}$ & \multicolumn{1}{c}{$\tau$} & $M_{f}{ }^{*}$ & $M_{m}{ }^{*}$ & $\begin{array}{c}b \\
\mathrm{kPa}\end{array}$ & $G^{\prime}$ \\
\hline CIDC-1 & 10 & 17000 & 0.042 & 1.5 & 1.23 & 50 & 500 \\
CIDC-2 & 35 & 19000 & 0.014 & 1.25 & 1.23 & 50 & 500 \\
CIDC-3 & 60 & 20000 & 0.010 & 0.98 & 1.23 & 50 & 500 \\
CIUC-1 & 23 & 18000 & 0.018 & 1.5 & 1.23 & 50 & 500 \\
CIUC-2 & 44 & 19500 & 0.013 & 1.5 & 1.23 & 50 & 500 \\
CAUC-1 & 36.6 & 19000 & 0.014 & 1.5 & 1.23 & 50 & 500 \\
\hline
\end{tabular}

For CAUC-1, initial deviator stress $\sigma_{11}{ }^{\prime}-\sigma_{33}{ }^{\prime}$ is $28 \mathrm{kPa}$.

$\sigma_{m(0)}{ }^{\prime}:$ an initial mean effective stress

$G_{0}:$ Elastic shear modulus (initial value of $d q / d \varepsilon_{1}$ )

$\sigma_{m c^{\prime}}=198 \mathrm{kPa}$

$\sigma_{m b^{\prime}}=120 \mathrm{kPa}$

$-\tau$ indicates the degree of strain-softening of the material; it is large at low stresses and becomes equal to 0 at the intersection of the limit state curve with $\phi^{\prime}$ line of the soil normally consolidated. Fig. 7 shows a typical relationship between $\tau$ and $\sigma_{m(0)}{ }^{\prime}$ and the data giving the best fit for the tests simulated.

$-M_{f}^{*}$ is the large strain strength parameter; its variation reflects the curvature of the strength envelope (Lefebvre and La Rochelle, 1974 ; Tremblay, 1983).

$-M_{m}{ }^{*}$ is the strength parameter corresponding to the friction angle of the normally

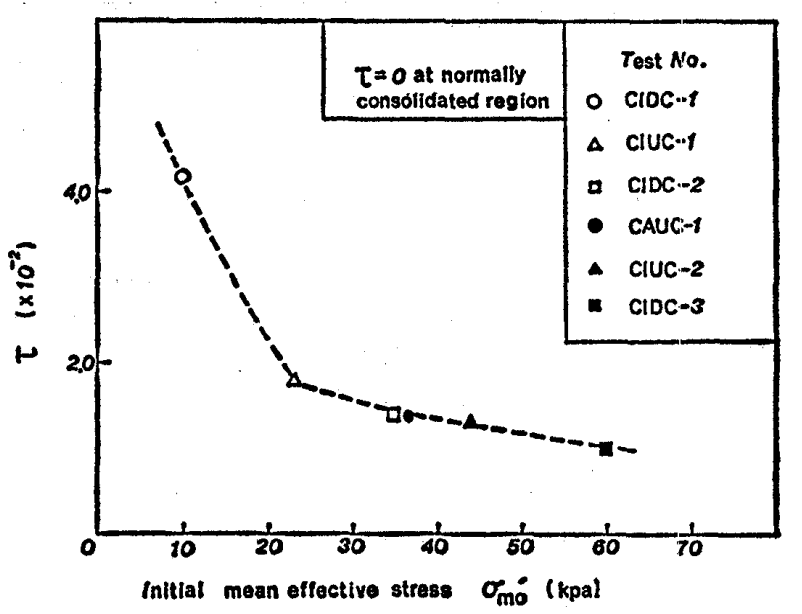

Fig. 7. Parameter $\tau$ versus initial mean eff ective stress use of Louisevill clay

consolidated soil $\left(\phi^{\prime}=30\right.$ degree for the Louiseville clay).

\section{DRAINED TRIAXIAL COMPRESSION TEST}

Figs. 8-10 show isotropically consolidated drained triaxial compression test results (CIDC test). For drained tests, the strain rate for shearing was $0.1 \% / \mathrm{h}$. Fig. 8 provides a typical stress-strain relation for CIDC 


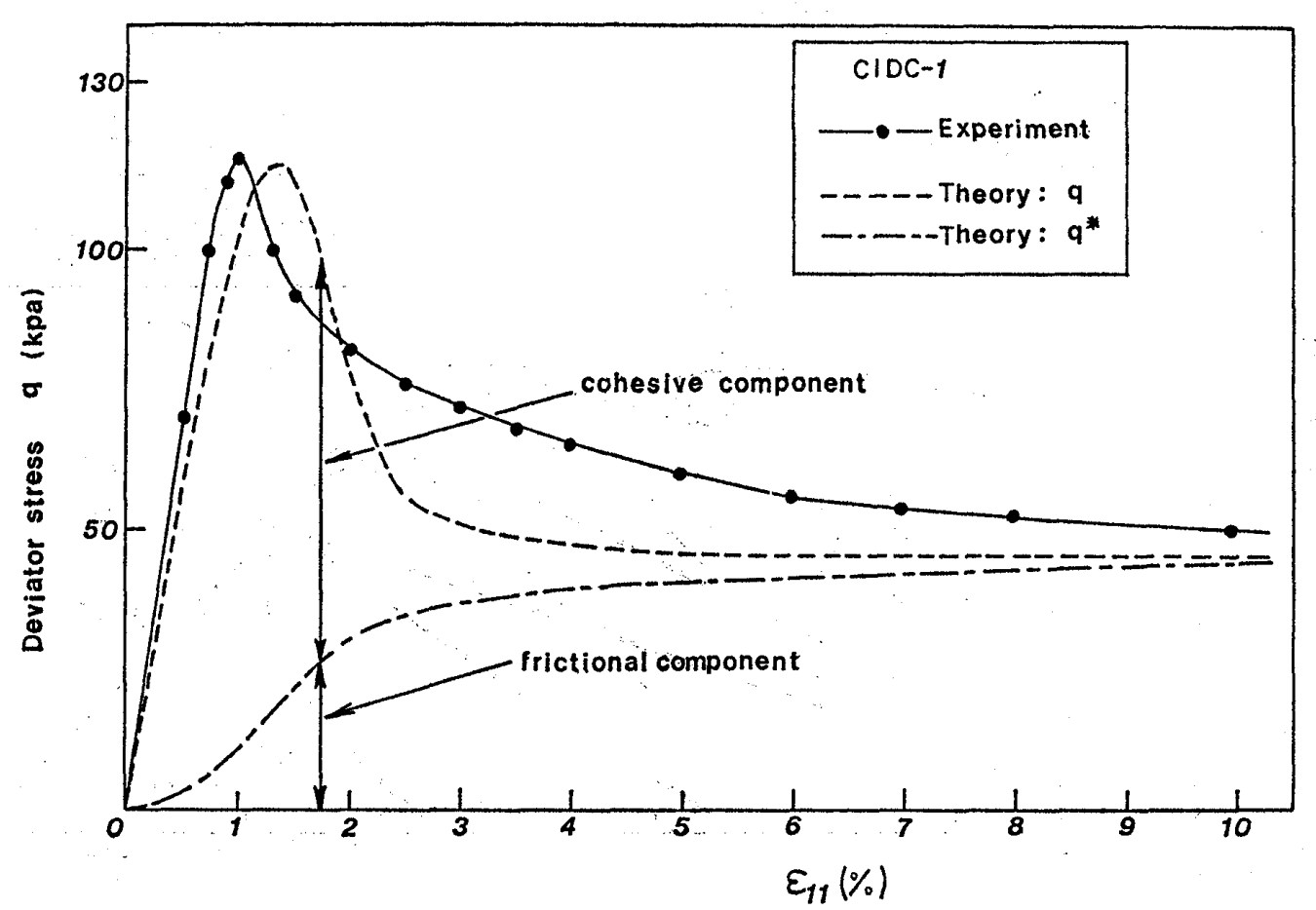

Fig. 8. Stress-strain relation for CIDC-1 test

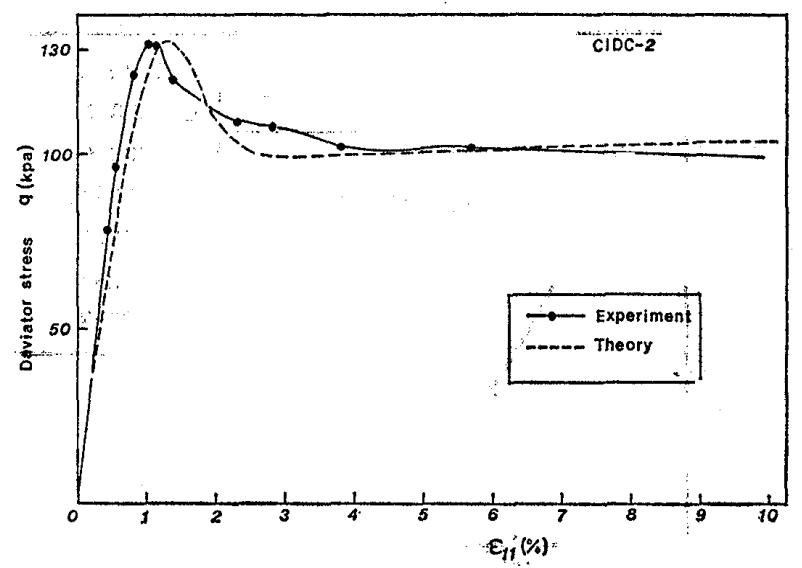

Fig. 9. Stress-strain relation for CIDC-2 test

test. Before peak, the material is elastic and after, the strength of the material decreases and approaches the large strain strength state. In this figure, the result of model simulation is also presented. Dashdot-line denotes the relationship between the deviator stress history $q^{*}$ and axial strain relation. With the increase of axial strain, deviator stress $q$ becomes equal to $q^{*}$ so that $q-q^{*}$ decreases during the deformation. $q^{*}$ can be interpreted as the frictional component of shear strength and

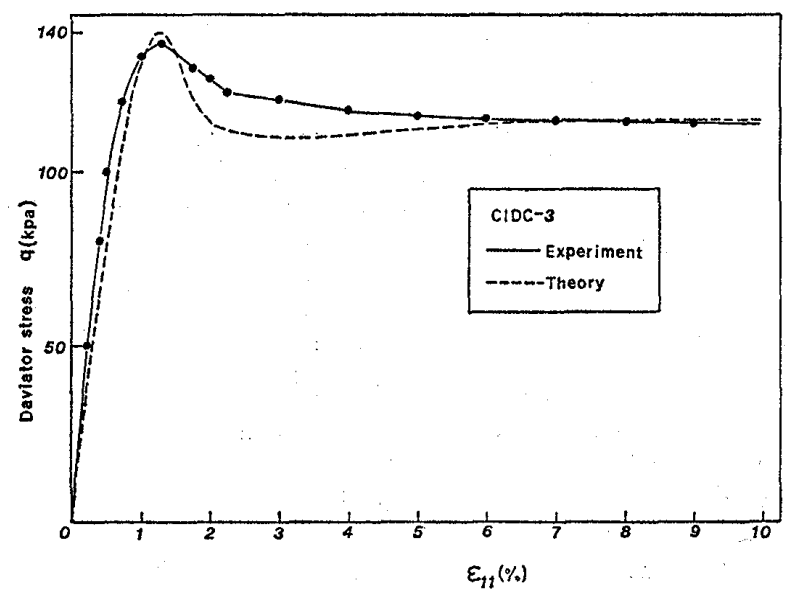

Fig. 10. Stress-strain relation for CIDC-3 test

$q-q^{*}$ corresponds to the component of the shear strength due to bonding, cohesion or reasons other than the frictional resistance. The strain-softening behavior can be interpreted as the process in which the material is destructured and the shear resistance due to cohesion decreases.

It is notable that $q^{*}$ is developed in the early stages of deformation before peak strength. From a physical point of view, it is reasonable that the microstructure change 


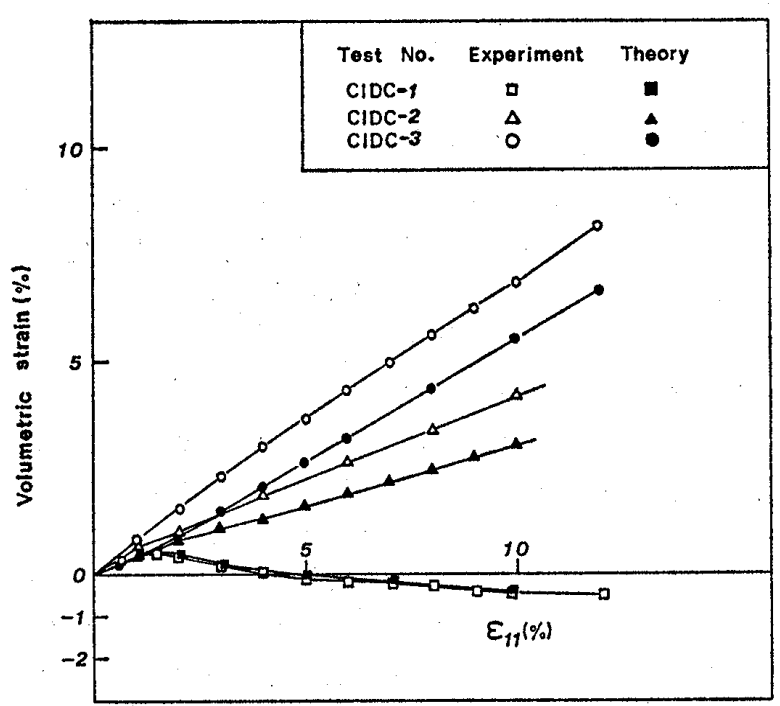

Fig. 11. Volumetric strain versus axial strain relation for CIDC tests

or failure begins even in the low deviator stress level. Concerned with the components of strength as a function of strain, Kovari (1982) proposed a schematical figure for rocks, which is similar to Fig. 8 . He set up the lower limit of strain where the microfailure of material occurs. In the present model, the lower limit of strain for the development of frictional strength is not assumed. In Figs. 8-10, the experimental and predicted results of stress-strain curves in CIDC tests are plotted. These figures show that the proposed model can reasonably explain the behavior of O.C. clay during CIDC test. Going into details of stressstrain curves, during the strain-softening process just after the peak, the decreasing rate of deviator stress in experimental results is relatively lower than the calculated ones. In Fig. 11, the calculated volumetric strainaxial strain relations are compared with the experimental results. Compression is observed after peak strength is reached in CID-2 and CID-3, while the mean effective stress decreases.

Although the numerical result for case CIDC- 1 is very close to the experimental result, compressive volumetric strains for cases CIDC- 2 and CIDC- 3 are slightly smaller than measured values. This difference between simulated and measured volumetric

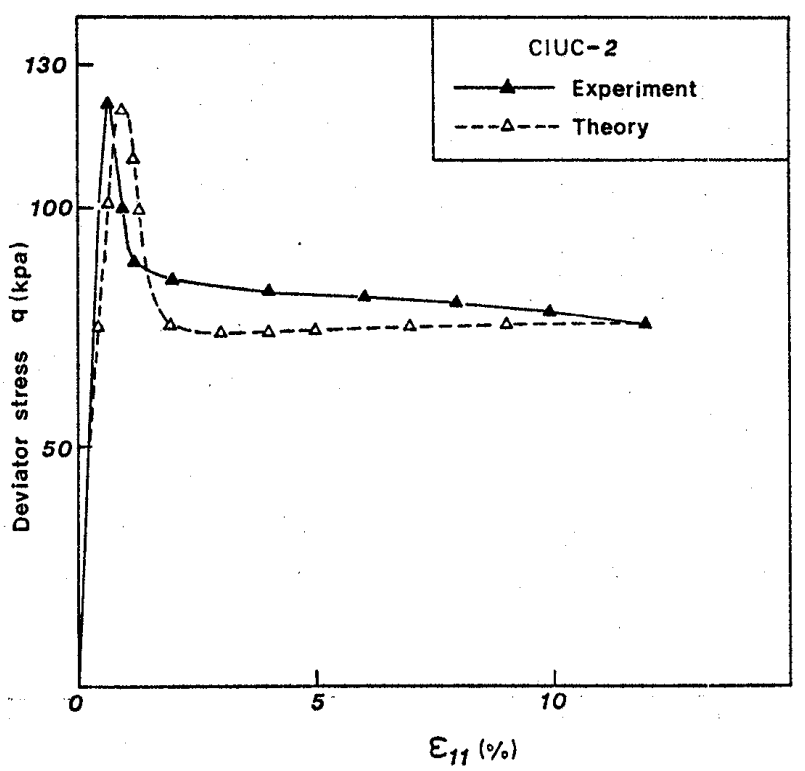

Fig. 12. Stress-strain relation for CIUC-2 test

strains comes essentially from the shape of the plastic potential function, indicating that more theoretical work is necessary to improve the plastic potential function. However, the overall trend agrees well with the experimental results.

\section{ISOTROPICALLY CONSOLIDATED UN- DRAINED TRIAXIAL COMPRESSION TEST}

In the CIUC-tests, clay specimens were sheared under undrained conditions.: The strain rate was $0.5 \%$ /hour. Fig. 12 shows a typical comparison between the experimental stress-strain relation and the simulated one. As can be seen, just after the peak strength is reached, the reduction of the shear strength in simulated result is larger than that of experimental one. Fig. 13 shows the stress paths for CIUC and CAUC tests. The simulated stress paths are close to the experimental results.

\section{ANISOTROPICALLY CONSOLIDATED UNDRAINED TRIAXIAL COMPRES- SION TEST}

In CAUC test, the clay specimen was 
anisotropically consolidated under the condition $K=\sigma_{3}{ }^{\prime} / \sigma_{1}{ }^{\prime}$ equal to 0.75 and sheared under undrained conditions. The strain rate was $0.5 \% / \mathrm{h}$. Both simulated stress-strain curve (Fig. 14) and stress path (Fig. 13) show a good agreement with feature of CAUC test. As for CAUC test the decrease of the deviatoric stress after the peak strength is more rapid for the simulated test than for the experiment.

Fig. 13 also shows the trend for the three stress paths in undrained tests to go at large strain towards the same end point. This corresponds to one of the important experi-

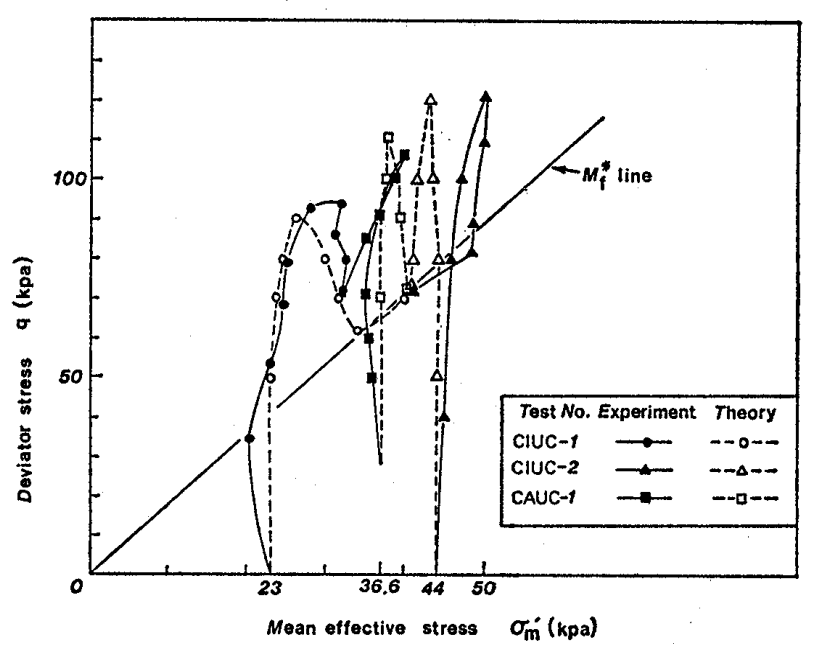

Fig. 13. Stress paths for consolidasted undrained triaxial tests

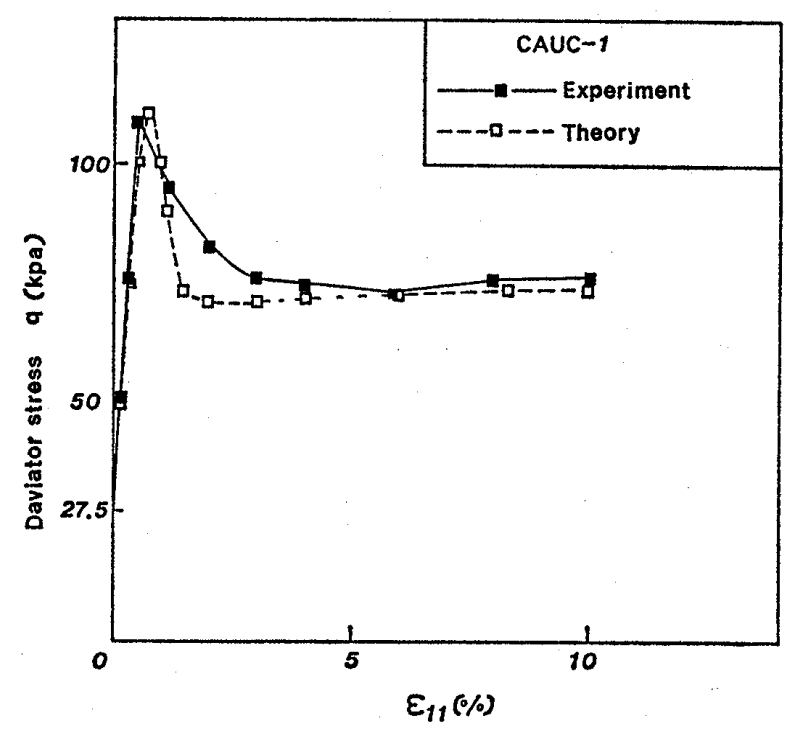

Fig. 14. Stress-strain relation for CAUC test mental evidence.

\section{CONCLUSIONS}

In the present paper, a constitutive model for natural overconsolidated clay with strainsoftening is developed based on the elasto/ plastic constitutive theory for overconsolidated clay (Adachi and Oka, 1984) and the stress history tensor. The proposed constitutive model is applied to the triaxial behavior of a natural overconsolidated clay obtained from eastern Canada (Champlain sea clay). The comparison between the simulated results and the experimental results indicates that the proposed theory is capable of describing the strain-hardening and strainsoftening plastic behavior which is important feature of natural soft clay. When applying the proposed model in FEM calculation, the generalization using the nonlocal continuum formulation (Bažant et al., 1988) might be usefull to overcome the mesh size dependency.

\section{ACKNOWLEDGEMENT}

The triaxial experiment was carried out at Laval University. Part of this research was supported by the Japanese Society for Promotion of Science, the National Research Council of Canada and Laval University.

\section{REFERENCES}

1) Akai, K., Adachi, T. and Oka, F. (1981): "Constitutive models for clays and sands," Proc. of the Workshop on Limit Equilibrium, Plasticity and Generalized Stress-Strain in Geotechnical Engineering, ASCE, pp. 815-838.

2) Adachi, T. and Oka, F. (1984): "Constitutive equations for sands and overconsolidated clays," Results of Int. Workshop on Constitutive Relations for Soils, Grenoble 1982, edited by Gudehus and Darve, Balkema, pp. 141-157.

3) Bažant, Z. P. and Pijaudier-Cabot, G. (1988): "Nonlocal continuum damage, localization instability and convergence," J. of Applied Mechanics, ASME, Vol. 55, pp. 287-293.

4) Bannerjee, P. K. and Stipho, A. S. (1979): “An 
elasto-plastic model for undrained behaviour of sheavily overconsolidated clays," Short Communication, Int. J. Numerical and Analytical Methods in Geomechanics, Vol.3, pp. 97-103.

5) Christensen, R.M. (1982): Theory of Viscoelasticity- An Introduction, second edition, Academic Press.

6) Dragon, A. and Mróz, Z. (1979): "A continuum model for plastic-brittle behaviour of rock and concrete," Int. J. Engng. Sci., Vol.17, pp. 121-137.

7) El Mouatassim, M. (1986): "Comportement des argile naturelles à l'intérieur de la courbe d'état limite," M. SC. Thesis, Laval University, Québec.

8) Fauvea-Brucy, F. (1977): "Effect du passage en état normalement consolidé sur l'état limite d'une argile naturelle," M.Sc. Thesis, Laval University, Québec.

9) Félix, B., Magnan, J. P., Josseaume, H., Kenana, A., Piyal, M. and Shahanguian, S. (1985): "Comportement triaxial de l'argile molle de Cubzac," Proc. 11 th Int. Conf. SMFE, San Francisco, Vol.2, pp. 451-454.

10) Graham, J., Noonanm, M. L. and Lew, K. V. (1983): "Yield states and stress-strain relationships in a natural plastic clay," Canadian Geotechnical Journal, Vol.20, No.3, pp.502516.

11) ISSMFE Subcommittee (1985): "Constitutive laws of soils," Report of ISSMFE Subcommittee on Constitutive Laws of Soils and Proc. of Discussion Session 1A, XI ICSMFE, San Francisco, edited by S. Murayama, Pub. by JSSMFE.

12) Kawahara, M., Kanoh, Y., Kaneko, N. and Yada, K. (1981): "Strain-softening finite element analysis of rock applied to tunnel excavation," Proc. of Int. Symp. on Weak Rock, Tokyo, pp. 713-719.

13) Kondner, R. L. (1963): "Hyperbolic stressstrain response: Cohesive soils," J. SMFD, Proc. ASCE, Vol. 89, No. SM 1, pp. 115-143.

14) Kovari, K. (1982): "Rock mass behaviour and its mathematical modelling", Numerical Methods in Geomechanics, edited by J. B. Martin, Nato Advanced Study Institute Series, D. Reidel Pub. Company, pp. 145-164.

15) Lade, P. V. (1987): "Behavior and plasticity theory for metals and frictional materials," Constitutive Laws for Engineering Materials : Theory and Applications, edited by Desai et al., Vol. 1, pp. 327-334.

16) Larsson, R. (1981): "Drained behavior of
Swedish clays," Swedish Geotechnical Institute, Report No.12, 157 p.

17) Lefebvre, G. (1970): "Contribution à l'etude de la stabilité des pentes dans les argiles cimentées," Ph. D. Thesis, Laval University, Québec.

18) Lefebvre, G. and La Rochelle, P. (1974): "The analyses of two slope failures in cerrented Champlain clays," Canadian Geotechnical Journal, Vol.11, No.1, pp.89-108.

19) Leroueil, S., Tavenas, F., Brucy, F., La Rochelle, P. and Roy, M. (1979): "Behavior of destructured natural clays," ASCE Journal of Geotechnical Engng. Division, Vol.105 (GT 6), pp. 759-778.

20) Leroueil, S., Tavenas, F. and Le Bihan, J.P. (1983): "Propriétés caractéristiques des argiles de l'est du Canada," Canadian Geotechnical Journal, Vol.20, No.4, pp. 681-705.

21) Lo, K. Y. and Morin, J. P. (1972): "Strength anisotropy and time effects of two sensitive clays," Canadian Geotechnical Journal, Vol.9, No. 3, pp. 261-277.

22) Magnan, J. P., Shahanguian, S. and Josseaume, H. (1982): "Etude en laboratoire des limites d'une argile molle organique," Revue Francaise de Geotechnique, No. 20, pp. 13-19.

23) Matsumoto, T. and Ko, H.Y. (1982): "Finite element analysis of strain-softening soils," Proc. of 4 th Int. Conf. on Numerical Methods in Geomechanics, Vol.1, pp. 213-222.

24) Nayak, G.C. and Zienkiewicz, O.C. (1972): "Elasto-plastic stress analysis; A generalization for various constitutive relations including strain-softening," Int. J. Numerical and Analytical Methods in Geomechanics, Vol.5, pp. 113-135.

25) Nishi, K. and Esashi, Y. (1978): "Stress--strain relationships of sand based on elasto-plasticity theory," Proc. of JSCE, Vol.280, pp. 111-122.

26) Ohmaki, S. (1980) : "Elastic behavior of normally consolidated clay," Proc. of 3 rd Australia-New Zealand Conference on Geomechanics, Vol. 2, pp. 127-132.

27) Oka, F. and Washizu, H. (1981): "Constitutive equation for sands and overconsolidated clays under dynamic loads based on elasto-plasticity," Proc. of Int. Conf. on Recent Advances in Geotechnical Earthquake Engng. and Soil Dynamics, St. Louis 1981, Vol.1, pp. 71-74.

28) Oka, F. (1985) : "Elasto/viscoplastic constitutive equations with memory and internal variables," Computers and Geotechnics, Vol.1, pp. 59-69. 
29) Oka, F. and Adachi, T. (1985): "An elastoplastic constitutive equation of geologic materials with memory," Proc. of 5 th Int. Conf. Numerical Methods in Geomechanics, Vol.1, pp. 293-300.

30) Oka, F. and Adachi, T. (1985): "A constitutive model of soft rock with strain-softening," Proc. of Discussion Session $1 \mathrm{~A}$, Constitutive Laws of Soils, JSSMFE, 11 th ICSMFE, San Francisco, pp. 152-155.

31) Pender, M. J. (1977) : “A unified model for soil stress-strain behaviour," Constitutive equations of Soils, Specialty Session 9, 9 th ICSMFE, pp. 213-222.

32) Perzyna, P. (1970): "Memory effects and internal changes of material," Int. J. Non-Linear Mechanics, Vol.6, pp. 707-746.

33) Pietruszczak, S. and Mróz,Z. (1981): "Finite element analysis of strain softening materials," Int J. Numerical Methods in Engng., Vol.17, pp. 327-334.

34) Prévost, J. -H. and Höeg, K. (1975) : "Soil mechanics and plasticity analysis of strain softening," Geotechnique, Vol.25, No.2, pp. 279-297.

35) Roscoe, K. H., Schofield, A. N. and Wroth, C.P. (1985): "On the yielding of soils," Géotechnique, Vol.8, No.1, pp. 22-53.

36) Sekiguchi, H. and Ohta, H. (1977): "Induced anisotropy and time dependency in clays," Proc. of Speciality Session 9, 9 th ICSMFE, pp. 229-238.

37) Stipho, A.S. A. (1980): "Incremental elastoplastic constitutive relationships for strainsoftening "Stiff" clays," Numerical Methods for Engineering, 2 nd International Congress, edited by Absi et al., pp. 685-703.

38) Tavenas, F. and Leroueil, S. (1977): "Effects of stresses and time on yielding of clays," Proc. of 9 th ICSMFE, Tokyo, Vol.1, pp. 319-326.

39) Tavenas, F. and Leroueil, S. (1979): "Clay behavior and the selection of design parameters," Proc. 7 th European Conf. on SMFE, Brighton, Vol. 1; pp. 281-291.

40) Tavenas, F., Leblond, P. Jean and Leroueil, S. (1983): "The permeability of natural clays. Part I: Method of laboratory measurement," Canadian Geotechnical Journal, Vol.20, No.4, pp. 629-644.

41) Tavenas, F. and Leroueil, S. (1987): "Stateof-the-art on laboratory and in-situ stressstrain-time behavior of soft clays, "Int. Symp. on Geotechnical Engng. of Soft Soils, Mexico, Vol. 2.

42) Trembly, M. (1983): "Etude cpmparative des paramètres de résistance des argile de l'est du Canada," M. Sc. Thesis, Laval University, Québec.

43) Valanis, K. C. (1971) : "A theory of viscoplasticity without a yield surface. Part I," Arch. of Mechanics, Vol.23, pp. 517-533., Part II, Arch. of Mechanics, Vol.23, pp. 535-551.

44) Valanis, K. C. and Read, H.E. (1982) : "A new endochronic plasticity model for soils," Transient and Cyclic Loads, edited by G. N. Pande and O.C. Zienkiewicz, pp. 375-417.

45) Valanis, K.C. (1985): "On the uniqueness of solution of the initial value problem in softening materials," Journal of Applied Mechanics, ASME, Vol. 52, pp. 649-653.

46) Wang, C. - C. (1969): "Generalized simple body," Archive for Rational Mechanical Analysis, Vol. 32, pp. 1-30.

47) Willam, K., Pramono, E. and Sture, S. (1987): "Uniqueness and stability issues of strain softening computations," Constitutive Laws for Engineering Materials, edited by Desai et al., Vol. 1, pp. 249-260.

48) Wong, P. K. K. and Mitchell, R. J. (1975): "Yielding and plastic flow of sensitive comented clay," Geotechnique, Vol.25, No.4, pp.763782. 